\title{
12 Linnaean paper tools
}

In this chapter, I am going to explore a theme that has recently become a 'hot topic' in cultural studies of early modern science and medicine more generally: the use of ink-and-paper tools, both in script and print, to accumulate, process and communicate information across geographic, socio-political and cultural distances. This is a topic that promises to deepen our understanding of the history of natural history, especially in its 'classical' period, which stretches between the tenth edition of Carl Linnaeus's Systema naturae (1758) and Charles Darwin's On the Origin of Species (1859). ${ }^{1}$ In the first section, I shall provide an outline of the information economy of classical natural history, contending that it was characterised by an increasing heterogeneity, rather than homogeneity, of sources of knowledge. In the second section, I shall argue that the adoption of two information-processing devices that Linnaeus had introduced - namely binomial nomenclature and the so-called hierarchy of taxonomic ranks - gave discursive unity to classical natural history despite this heterogeneity. The third section, finally, will present some examples of how these devices were deployed in the form of paper tools designed for the storage, indexing and exchange of information on plants and animals. Overall, I want to suggest that attention to the material construction and practical deployment of such paper tools can tell us a lot about natural history and its highly dynamic research culture.

\section{The information economy of classical natural history}

Late eighteenth and early nineteenth-century natural history experienced social and institutional changes that involved both diversifying and centralising tendencies. On the one hand, rising levels of literacy and the spread of cheap print made it increasingly easier to consume, and contribute to, natural history, resulting in a widening basis of amateur naturalists engaged in specimen collection and epistolary exchange, and the formation of local and 
regional associations of naturalists. ${ }^{2}$ Moreover, demand increased for expert naturalists to fill positions both in the context of state bureaucracies, economic enterprises, and organisations engaged in long-distance trade and colonial administration. ${ }^{3}$ These experts both contributed to, and depended upon, the production, exchange and consumption of information on minerals, plants and animals, their properties and their uses. The 'information economy' of natural history began to offer a crucial stepping stone for members of the middling sort and subalterns to enter various occupations and careers of an administrative, brokering or entrepreneurial nature. ${ }^{4}$

Until the mid eighteenth century, the exchange of specimens, letters and publications centred on individuals. Linnaeus in Sweden, Georges-Louis Leclerc, comte de Buffon in France, Hans Sloane and Joseph Banks in England, Herman Boerhaave in the Netherlands and Albrecht von Haller in Switzerland are just a few among the naturalists who personally managed and controlled vast social networks. Along with the letters they exchanged, they received specimens accompanied by written information and drawings, as well as manuscripts and publications. ${ }^{5}$ By the early nineteenth century, central institutions that were there to stay had taken over this role, such as the Muséum national d'Histoire naturelle in Paris, Kew Gardens and the British Museum in London and Berlin University with its newly established gardens and collections in Prussia. ${ }^{6}$ Individuals associated with these institutions certainly continued to wield enormous power over information flows in natural history. ${ }^{7}$ But two important structural features distinguished the 'new' museums from their early modern counterparts. $^{8}$ First, they represented collections of collections rather than collections tout court. Often starting out with the acquisition of a single large collection, these museums then expanded by acquiring further collections, or by commissioning travelling naturalists to hunt for specimens on a global scale. The most striking example of this is the Muséum national d'Histoire naturelle in Paris, which received a boost from the confiscation of aristocratic collections during the French Revolution, the provenance of which was carefully noted in a catalogue. ${ }^{9}$ Second, and concomitantly, museums became increasingly articulated into specialised departments, offering hierarchically organised positions for curators or 'keepers' and various amanuenses who administered its collections. A new generation of 'professional' naturalists emerged, often socialised through participation in long-distance natural historical exploration, during 
which they collected for their patrons or institutions, and later moving on to curatorial work in metropolitan collections and libraries. ${ }^{10}$

The knowledge networks that underwrote natural history were not just expanding and diversifying in the late eighteenth and early nineteenth centuries. Rather, over the same period, institutions emerged which formed central hubs in these networks and appropriated the knowledge that was generated. This double process of diversification and centralisation turned natural history into an increasingly disparate and tension-ridden field. Numerous conflicts testify to this and, as one might expect from the complexity of the developments just outlined, they did not align with a simple centre-periphery dichotomy. To be sure, tensions existed between imperial ways of practising natural history and their colonial and indigenous counterparts. ${ }^{11}$ But such conflicts played out with equal intensity on a regional scale between local naturalists and metropolitan experts, both within European nations and within their nascent colonies. ${ }^{12}$ They even occurred on the microscale, within local institutions and associations, where professional and disciplinary standards, as well as social status and authority, were at stake. ${ }^{13}$

To date, 'information economy' largely remains a suggestive metaphor; the conceptual tools for studying the actual economic mechanisms that supported and propelled natural history during its classical period still need to be developed. ${ }^{14}$ But the metaphor draws attention to the infrastructures that mediated information exchange in classical natural history. ${ }^{15}$ In order to gain a better understanding of these infrastructures, the next section will turn to two innovations that formed the cornerstones of Linnaeus's selfstyled 'reform' of natural history - the naming of plant and animal species by 'trivial' names composed of genus name and specific epithet (as in Homo sapiens); and their ordering in a hierarchy of taxonomic ranks, by variety, species, genus, order (or family) and class. By the end of the eighteenth century, both of these innovations had been universally adopted by naturalists, and as the few analyses of their reception that exist demonstrate, it was precisely their practical value in communication that made them so attractive to naturalists in their pursuit of ever-enhanced levels of collaboration and information exchange in natural history. ${ }^{16}$

\section{Linnaean paper tools}

One of the most astonishing aspects of classical natural history is the success that Linnaeus's taxonomic publications enjoyed in 
terms of print run, especially if one considers that these were not publications made for leisurely reading or intellectual entertainment, but catalogues filled with names of genera and species, references to earlier literature, short morphological diagnoses and abbreviations designating geographic range and ecological habitat. Linnaeus himself counted twelve editions of his Systema naturae between 1735 and 1768 - expanding over that time from a single eleven-page folio volume to four octavo volumes numbering 2,441 pages in total - six editions of Genera plantarum from 1737 to 1764 , and two editions of Species plantarum (1753 and 1762). Moreover, the success of the books far outlived Linnaeus himself. From the late 1760 s onwards, but especially after Linnaeus's death in 1778 , other naturalists began to publish new editions, translations and adaptations of his works. Some of these continued Linnaeus's own numbering of editions, so there exists a sixteenth edition of the botanical part of Systema naturae, which was issued in Göttingen as Systema vegetabilium in five volumes from 1825 to 1828 , a two-volume ninth edition of Genera plantarum (Göttingen, 1830-1), and an aborted sixth edition of Species plantarum (Berlin, $1831-3) .^{17}$

The lasting success of Linnaeus's taxonomic work is often explained by claiming that it provided naturalists with the means to communicate unambiguously about plant and animal kinds (Figure 12.1). But what allows for unambiguous reference in modern taxonomy is the type method: the practice of associating taxonomic names with type specimens. And this method was only introduced to natural history towards the end of the nineteenth century. ${ }^{18}$ Linnaeus himself, when introducing binary names and the five-tiered hierarchy of taxonomic ranks, advertised quite a different advantage. Traditional or 'legitimate' names, as Linnaeus called them, were composed of the genus name and a diagnostic phrase that spelled out the traits by which the named species differed from other species of the same genus. The 'trivial' or binary name, in contrast, just added a 'single word ... freely adopted from anywhere' to the generic name. The trivial name was thus not only shorter and more easily reproduced; above all, it was more stable, since it did not have to carry any diagnostic meaning, and hence did not have to be changed whenever new species were discovered. ${ }^{19}$ In highlighting the advantage of a 'systematic' arrangement by class, order, genus, species and variety, Linnaeus drew on a similar contrast with traditional systems, whose primary function was also diagnostic. Whereas such diagnostic systems, or 'keys', guided naturalists 'along their way' in identifying organisms with known kinds by 


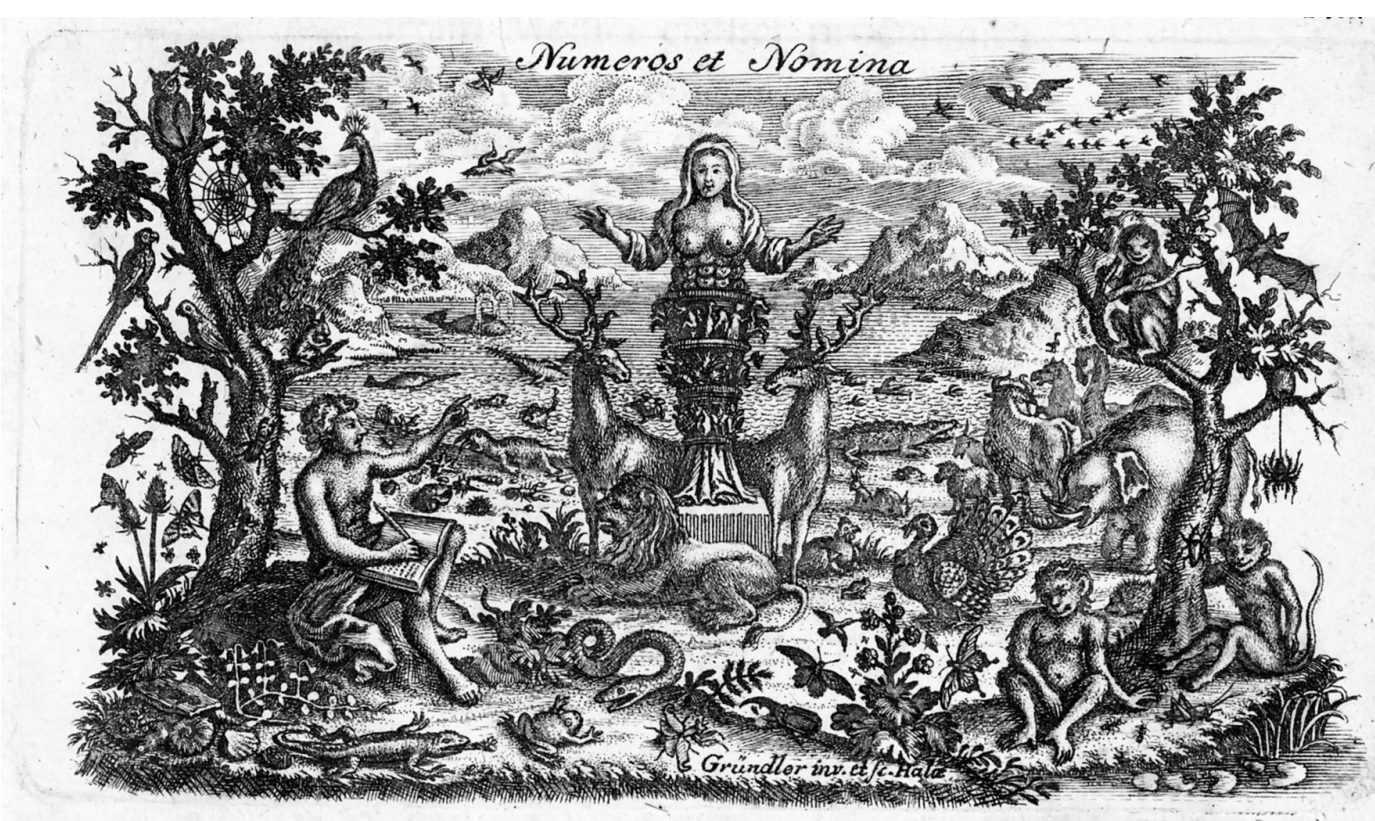

Figure 12.1 Frontispiece of the first volume of Caroli Linnaei ... Systema Naturae, edited by J. J. Lang (Halle, 1760). The frontispiece shows a statue of Diana, and is a variation of the frontispiece of Linnaeus's Fauna suecica (Leiden, 1746), adding a human figure taking notes and pointing to a monkey in the top of the tree to the right. The heading refers to 'numbers and names' (numeros et nomina) as essential elements of Linnaean natural history. Courtesy Uppsala University Library.

applying progressively narrower sets of criteria, they could not stake out the 'borders' of these kinds, i.e., circumscribe them as groups or collections of organisms. ${ }^{20}$ The identity of the taxa constituting the Linnaean hierarchy was determined not by any particular difference they happened to exhibit with respect to other taxa, but by what they contained, and came to contain - each genus containing a particular set of species, each order a particular set of genera, and so on.

In short, Linnaean names served a mere indexing function, like labels, while the Linnaean hierarchy simply provided a nested set of containers, of 'boxes within boxes' ${ }^{21}$ To gain a better understanding of how they facilitated communication among naturalists, it is useful to look at the role Linnaean names and taxa played in the creation of paper tools - the devices made from paper and ink, whether in manuscript or print, that were employed in practices of extracting, storing 
and processing written information, including note-taking, listing, cataloguing or tabulating. ${ }^{22} \mathrm{Up}$ to the early eighteenth century, the predominant forms of scholarly annotation had been marginalia and topically organised commonplace books, that is, media that tended to fix information in relation to a relevant (con)text. ${ }^{23}$ The late seventeenth and eighteenth centuries witnessed a transition to more flexible paper tools, like loose files and card catalogues, and to more complex techniques of extracting, rearranging and displaying information, like forms, tables, diagrams and maps, often deployed for highly idiosyncratic purposes. ${ }^{24}$

Linnaeus participated in this transition, experimenting throughout his career with a diversity of annotation and filing systems, various forms of lists and tables, and, towards the end of his life, with paper slips that resemble index cards. In all of these media, Linnaean taxa carved out an allocated paper space - whether on the printed pages of a book, in a handwritten list or table, in the form of a file produced from folded paper sheets, or by cutting paper into small slips of a standard size - that was labelled with the name of a genus or species and then used to collect pieces of information under that name. Since names served as mere indexing devices, the resulting packages of information could be freely extracted from their context, and their contents inserted, or even redistributed, elsewhere, without losing their identity as long as the labels remained attached. ${ }^{25}$ As early as 1737 , Linnaeus used a remarkable metaphor to explain the role of generic names as mere labels: 'The generic name has the same value on the market of botany, as the coin has in the commonwealth, which is accepted at a certain price - without needing a metallurgical assay - and is received by others on a daily basis, as long as it has become known in the commonwealth. ${ }^{26}$ This metaphor clearly implies that Linnaean names and ranks derived their value by serving as a material vector for exchanging and accumulating information, rather than from any intrinsic meaning. Species plantarum, Genera plantarum and Systema naturae were designed to serve as templates for communal annotation, whether this took the form of creating a numbered list of named specimens sent to a correspondent, or whether an interleaved copy of one of these works was used to absorb new observations gathered from reading the latest literature, from a letter received, or in the field. Linnaeus himself employed copies of his own publications exactly for this purpose throughout his career (Figure 12.2). He was thus able to churn out one edition after another on the basis of information he received from correspondents and travelling students. There is growing evidence that other naturalists used Linnaeus's 


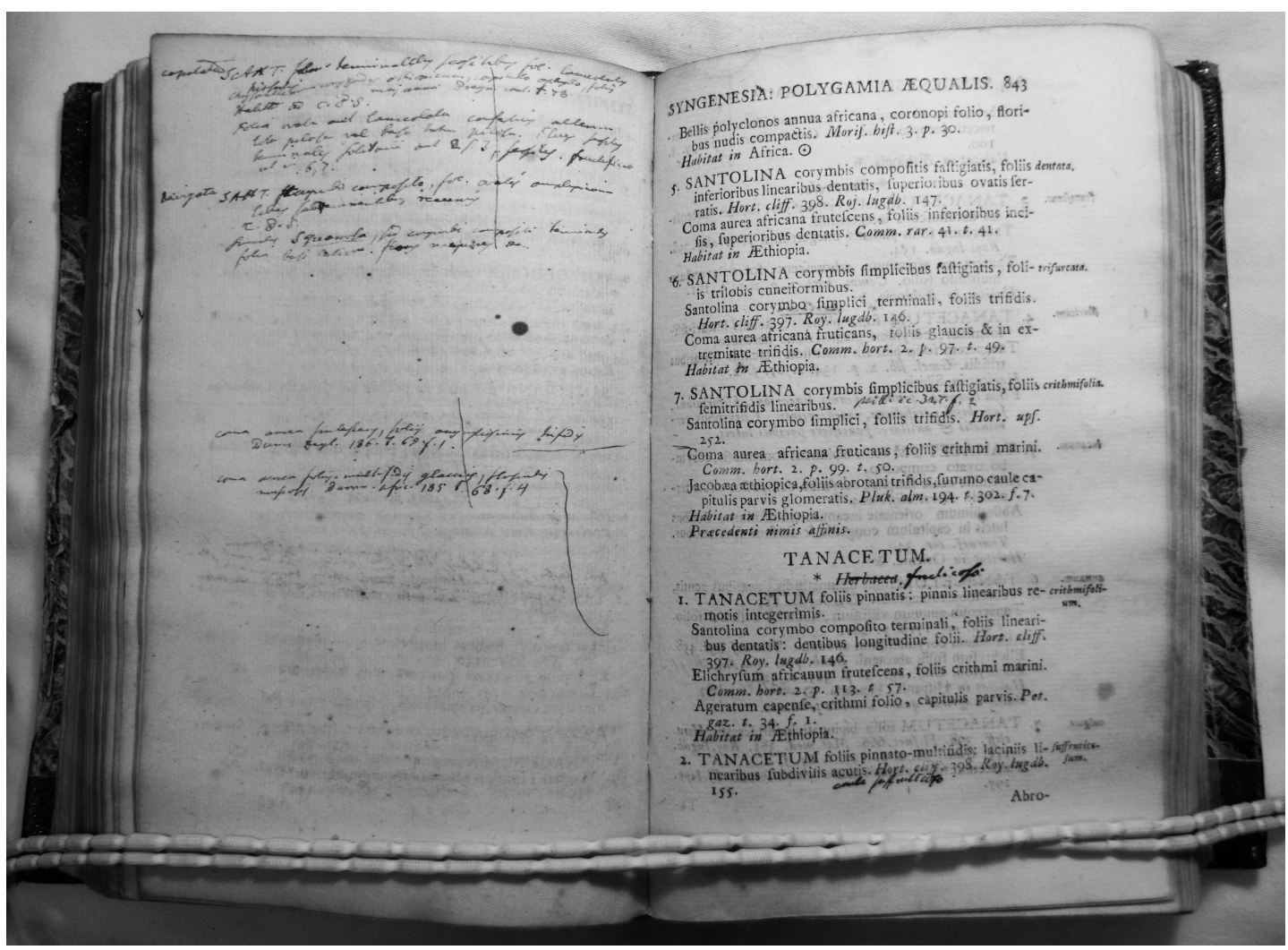

Figure 12.2 Page from Carl Linnaeus's own interleaved and annotated copy of his Species plantarum (Stockholm, 1753). Note that each entry for a species in the printed text follows a strict layout and order, and occupies roughly the same space. Each entry starts with a serial number and the genus name (in capitals), followed by a short diagnostic phrase distinguishing the species from other species of the same genus as well as references to works (in italics) that mention the species under that name. The genus name and the diagnostic phrase together form what Linnaeus called the 'legitimate' name of species. The subsequent paragraphs list 'synonyms', that is, alternative legitimate names under which the species was treated in the literature, again with references in italics. Most entries then end with a few short notes, partly employing symbols, containing additional information on geographic distribution, ecological habitat, life cycle, and taxonomic position. On the margin, against the first line of each entry, the specific epithet is noted in italics, which forms the 'trivial' name of each species together with the genus name. In addition, the text is structured by headings naming the genus. The page header spells out the class and order in Linnaeus's sexual system to which the genera treated on the page belong. Linnaeus's annotations were made in the preparation of a new edition of Species plantarum and include 
taxonomic works, and other works that built on his model, in the same way. ${ }^{27}$

The effects of the 'Linnaean reform' are evident in changes in the ways naturalists communicated with one another in letters. Rather than including elaborate descriptions, letters were often reduced to mere lists of names and references to Linnaeus's works, whether in instructing a correspondent or travelling naturalist about the minerals, plants or animals on which information was desired, or in reporting observations from a particular region, garden or collection. ${ }^{28}$ The ready availability of Linnaeus's books made it possible to reduce observations to emendations of or additions to those works; the reporting of errors became 'an essential component of the correspondence routine', as Bettina Dietz has argued, and was notably not perceived as an attack on the authority of the addressees of such reports. ${ }^{29}$ The overwhelming feedback that Linnaeus's own works generated in this form forced the Swedish naturalist to make recourse to an elaborate system of paper tools towards the end of his life; he would routinely reduce letters received to long, numbered lists of provisional binomial names, and then use the numbers and names to cross-reference the letters with herbarium specimens he had received, with his own manuscript notes on species that, at this stage in his career, he kept on small paper slips of standard size, and lastly with his taxonomic publications, which no longer appeared in the form of grand editions of Systema Naturae or Genera plantarum, but rather as supplements to these works, entitled Mantissa, a Latin word for makeweight, a small or worthless addition serving only to restore balance. $^{30}$

\section{Paper empires}

The fact that Linnaeus's taxonomic publications were most useful to naturalists because of the format in which they presented natural

Figure 12.2 (cont.) corrections and short additions that are entered directly in the printed text, and entries for new species and synonyms on the facing page. Note that the latter emulate the typographic layout of the printed text, and that the position where they are to be inserted is either directly indicated by their position on the page or with the help of a drawn line. Interestingly, in this case Linnaeus seems to have decided that two synonyms employing the same genus name, 'Coma', are to be distributed into two different genera ('Santolina' and 'Tanacetum'). Linnean Society, London, Library and Archives, Linnaean Collections, call no. BL83. Courtesy Linnean Society of London. 
historical knowledge explains one curious aspect of the many posthumous editions. Strictly speaking, these were not new editions or translations at all, but rather continuations of Linnaeus's taxonomic project, which incorporated new observations. ${ }^{31}$ Many of the editors of these works pointed this out explicitly. Thus, the Dutch physician and naturalist Martinus Houttuyn stated in the preface to his Natuurlyke Historie (1761-85) that he had adopted Linnaeus's 'system' and 'Latin bynames', i.e. Linnaeus's binominal or 'trivial' names. But he also stated that he had inserted information from publications by naturalists like Buffon or Jacob Theodor Klein, whose works rivalled those of Linnaeus in their scope and authority. ${ }^{32}$ The Frisian theologian and philosopher Philipp Ludwig Statius Müller, teaching cameralism and natural science at the University of Erlangen in Bavaria, made similar remarks in the preface to his German edition of Systema naturae, warning his readers in the very first sentence that they should 'not expect a translation', and then detailing his sources, notably Houttuyn's Dutch edition of Systema naturae, but above all the growing number of journal articles in natural history. ${ }^{33}$ In the preface to a supplementary volume, which appeared in 1776, Müller even asked his readers to report any new discoveries directly to him by providing, at the least, a short description and indication of the new species' taxonomic position. ${ }^{34}$ Müller unfortunately died before this supplementary volume appeared in print, but its publisher, Gabriel Nicolaus Raspe, explained in a short note that he was keen to continue the project. ${ }^{35}$ And indeed, between 1777 and 1779, Johann Friedrich Gmelin (1748-1804), Professor of Medicine at the University of Göttingen, edited four more volumes covering the mineral kingdom for Raspe, which were reprinted in 1785 . Thirteen volumes covering botany were edited by two other naturalists and appeared between 1777 and $1788 .^{36}$

One can see from this short sketch that translations and editions of Linnaeus's Systema naturae were products of complex, longterm paper work, not only because they often built on one another, rather than directly on Linnaeus's own publications (Figure 12.3), but also because their authors relied on a wide array of additional written sources - other general works in natural history, local floras and faunas, journal articles and letters from correspondents - to include the latest discoveries. Thus Gmelin acknowledged his material debt to 129 named naturalists in the preface of his own 'thirteenth' edition of Linnaeus's Systema naturae (1788-93). ${ }^{37}$ Müller coined a revealing expression for the unflagging compilatory activity that lay behind such works. In advertising his supplementary volume, he emphasised that 'all Addenda, Appendices and Mantissae of Herr von Linné have been properly slotted in (gehörig 


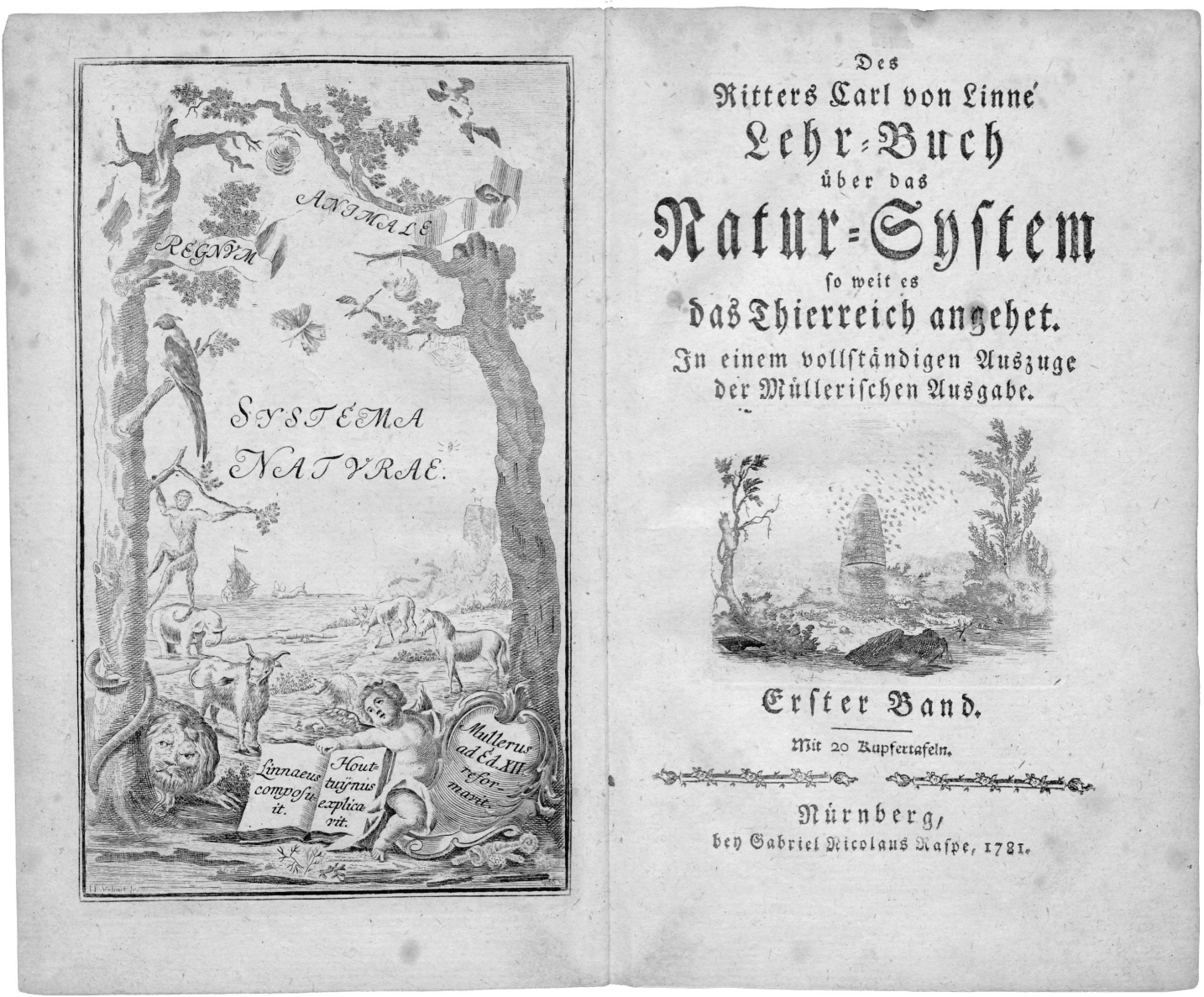

Figure 12.3 Frontispiece and title page of Des Ritters Carl von Linné Lehr-Buch über das Natur-System (Nürnberg, 1781). This was a shortened version of Philipp Ludwig Statius Müller's seven-volume Des Ritters Carl von Linné vollständiges Natursystem (Nürnberg, 1773-6) prepared by the clergyman Jeremias Höslin (1722-89) 'for everybody, rather than scholars', as it says in the preface. The inscriptions on the large volume and plaque held by a putto illustrate the succession of publications that the book builds on: 'Linnaeus composuit' points to the Swedish naturalist's tenth edition of Systema naturae, 'Houttuÿnius explicavit' to Houttuyn's expanded 'translation' of the tenth edition (started in 1761 and still ongoing at the time), and 'Mullerus ad Ed. XII reformavit' to Müller's attempt to provide a synthesis of Houttuyn's edition, Linnaeus's own twelfth edition of Systema naturae (1766-8), as well as other works. Courtesy Staatsbibliothek zu Berlin - PK | Abteilung Historische Drucke | Signatur: Le 2019. 
eingeschaltet)', and that the same had been done for new species reported by other naturalists. ${ }^{38}$

Einschalten is a verb with overtones of mechanical or bureaucratic labour, and simply means to insert an object into a preexisting series of other objects. ${ }^{39}$ It thus vividly expresses how easy it had become to compile data on plant and animal species since the Linnaean reform. Linnaean names and taxa empowered even those naturalists who, like Müller in Erlangen, were situated in peripheral contexts to build their own 'paper empires' on the basis of purely derivative literary techniques like extraction, compilation or rearrangement of names and accompanying descriptions. It is in this context, it seems, that even the more esoteric paper tools Linnaeus had developed, like the index cards he used in later life, began to spread, finding their way, for example, to the first two 'keepers' of botany at the British Museum, Linnaeus's own student Daniel Solander and Robert Brown. ${ }^{40}$

In order to demonstrate in more detail how Linnaean paper tools enhanced exchange, and especially, how they shaped naturalists' perceptions both of their own status and of the order of nature, I want to turn to a final example on a much smaller scale than those discussed so far. In 1768, the German naturalist Johann Reinhold Forster was commissioned to produce a volume on insects for Thomas Pennant's multivolume British Zoology. Just two years later, he published a curious first fruit of his labours, entitled A Catalogue of British Insects (Figure 12.4). It consisted of a list of slightly over 1,00o trivial names for insect species, neatly numbered consecutively, both overall and within each genus, and structured by headings giving the names of the genera to which the species belonged, which again were consecutively numbered. The overall purpose of the catalogue, as well as the meaning of the abbreviations set against many of its entries, were succinctly explained in the preface:

The author of this catalogue intends to publish a Fauna of British Insects; and as he thinks not to set out upon it, till he can offer to the public a work, as little imperfect as possible, and to give no other descriptions than from ocular inspection: he presents his most respectful compliments to all ladies and gentlemen who collect insects, and begs them to favour him, if possible, with specimens of such insects, as they can spare, and which he is not possessed of: for this purpose he has made this catalogue, and put no mark to the insects in his possession; those which he has so plentifully as to be enabled to give some of them to other collectors, are marked with a $(d)$; those which he has not, are marked either Berk. signifying Dr. Berkenhout's Outlines of the Natural History of Great 


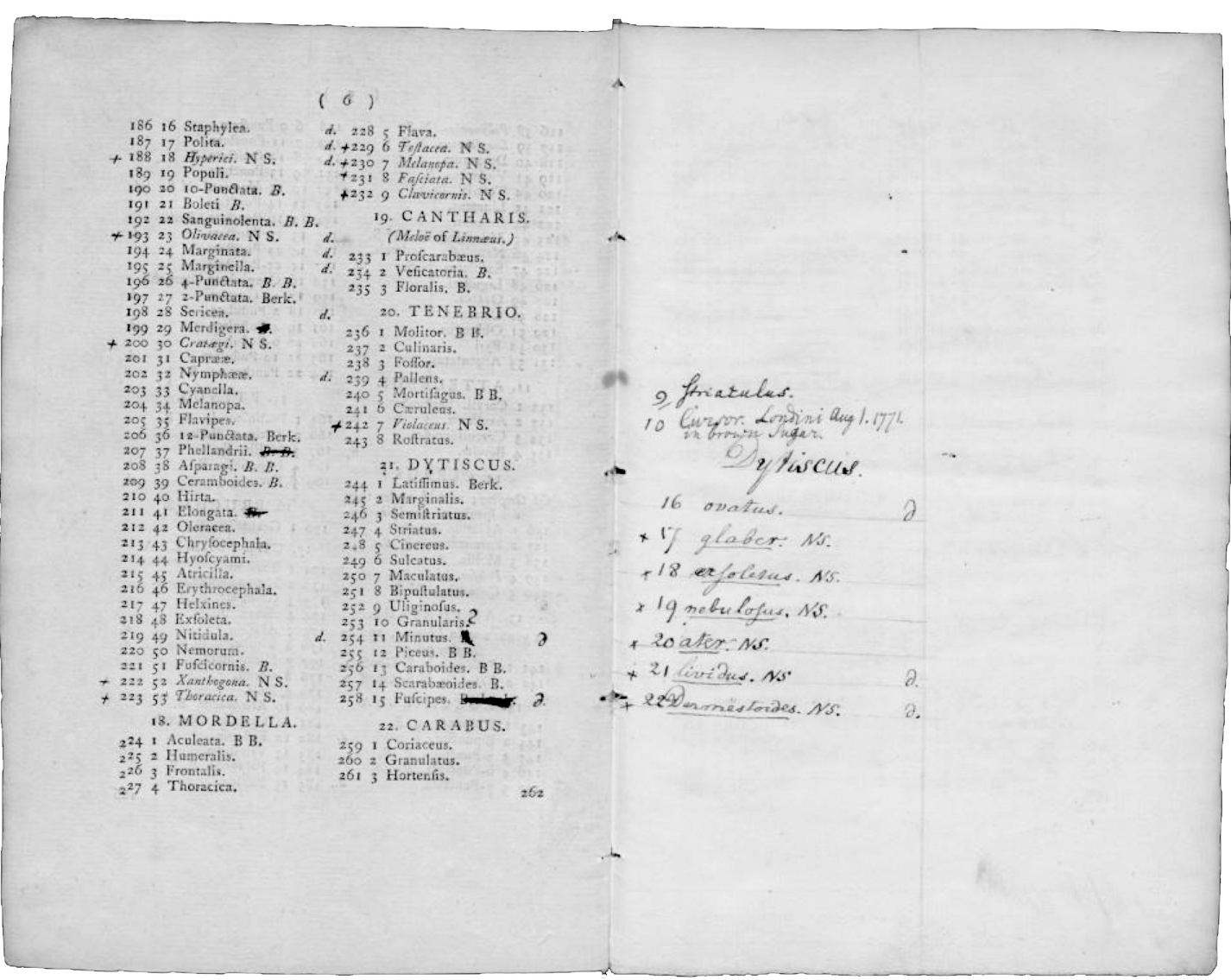

Figure 12.4 Two pages from the author's own annotated copy of Johann Reinhold Forster, A Catalogue of British Insects (Warrington, 1770). The printed text lists genera and species of insects, employing Linnaean trivial names. The notes document additional species that Forster came across after publication, many of them marked as new species ('N. S.'), and in one case reporting when and where the species was found: '10. [Tenebrio] Cursor. Londini Aug 1. 1771. in brown sugar'. The latter remark is probably referring to a beetle from Florida that later became known under that name among entomologists and which had been found in a shipment of sugar. See text for further discussion. Courtesy Staatsbibliothek zu Berlin - PK | Abteilung Historische Drucke | Signatur: Lt 12373.

Britain; or B. signifying a manuscript catalogue of British Insects communicated to the author; or $B$. $B$. which signifies Berkenhout, together with the manuscript catalogue. $N$. S. is put to such insects as have not yet been described by Dr. Linnaeus, and are new species with new specific names. ${ }^{41}$ 
At a glance, then, Forster's catalogue informed its readers how many species and genera of British insects were known to him, which of these he possessed in abundance (the ' $d$ ' probably standing for 'duplicate'), and which he was still looking for. ${ }^{42}$ The catalogue was an open invitation to enter into an exchange, and this tactical move was apparently successful. The Staatsbibliothek Berlin holds an interleaved copy of the Catalogue in which Forster carefully noted additions to his collection, by deleting the abbreviations 'Berk.', ' $B$.' or 'B.B.', by adding ' $d$.', or by noting additional species names on the interleaves, often followed by ' $N$. $S$.' and/or ' $d$.'. A note on the flyleaf of this copy states 'Aug. $\mathrm{y}^{\mathrm{e}}$ 28. 1771. 42 more insects', and a calculation at the very end of the catalogue registers ' 43 additional Insects' below the 1,004 already listed, and proudly draws up a new sum total of $1,047 .{ }^{43}$

Forster's Catalogue, with its extreme reduction of content to species names arranged according to the Linnaean hierarchy, illustrates the degree to which classical natural history was dominated by concerns with naturalists' position within the 'marketplace' of natural history. It is a document of book-keeping in an almost literal sense, recording credits and debits on the level of Forster's personal collection, and at the same time representing the British insect fauna itself in terms of abundance and scarcity of species. With regard to the latter, Forster's Catalogue shows striking structural similarities with what is certainly one of the most intriguing visual representations in late eighteenth-century natural history, the 'genealogical-geographical table of plant affinities' (Tabula genealogico-geographica affinitatum plantarum) that Paul Dietrich Giesecke produced on the basis of notes taken during private lectures he received from Linnaeus (Figure 12.5). The table represents the plant kingdom in the form of fifty-eight circles of varying size, distributed over the sheet in an unruly manner, a little bit like an archipelago. The explanations that accompanied the table indeed speak of a 'map', and of the circles as 'provinces' or 'islands', each of them standing for a particular 'natural order' of plants, their sizes corresponding to the number of genera they contained, and their mutual positions expressing relations of 'affinity'. ${ }^{44}$ The aims of Linnaeus's speculations about a 'natural' plant system may have been loftier than those of Forster's Catalogue, but his manuscript explorations of plant affinities took exactly the same form of numbered lists structured by headings, and were certainly of equal strategic importance in his dealings with other plant collectors. ${ }^{45}$

\section{Conclusion}

It should be emphasised that the evidence that I have used in this chapter about the use of paper tools in natural history is still very 


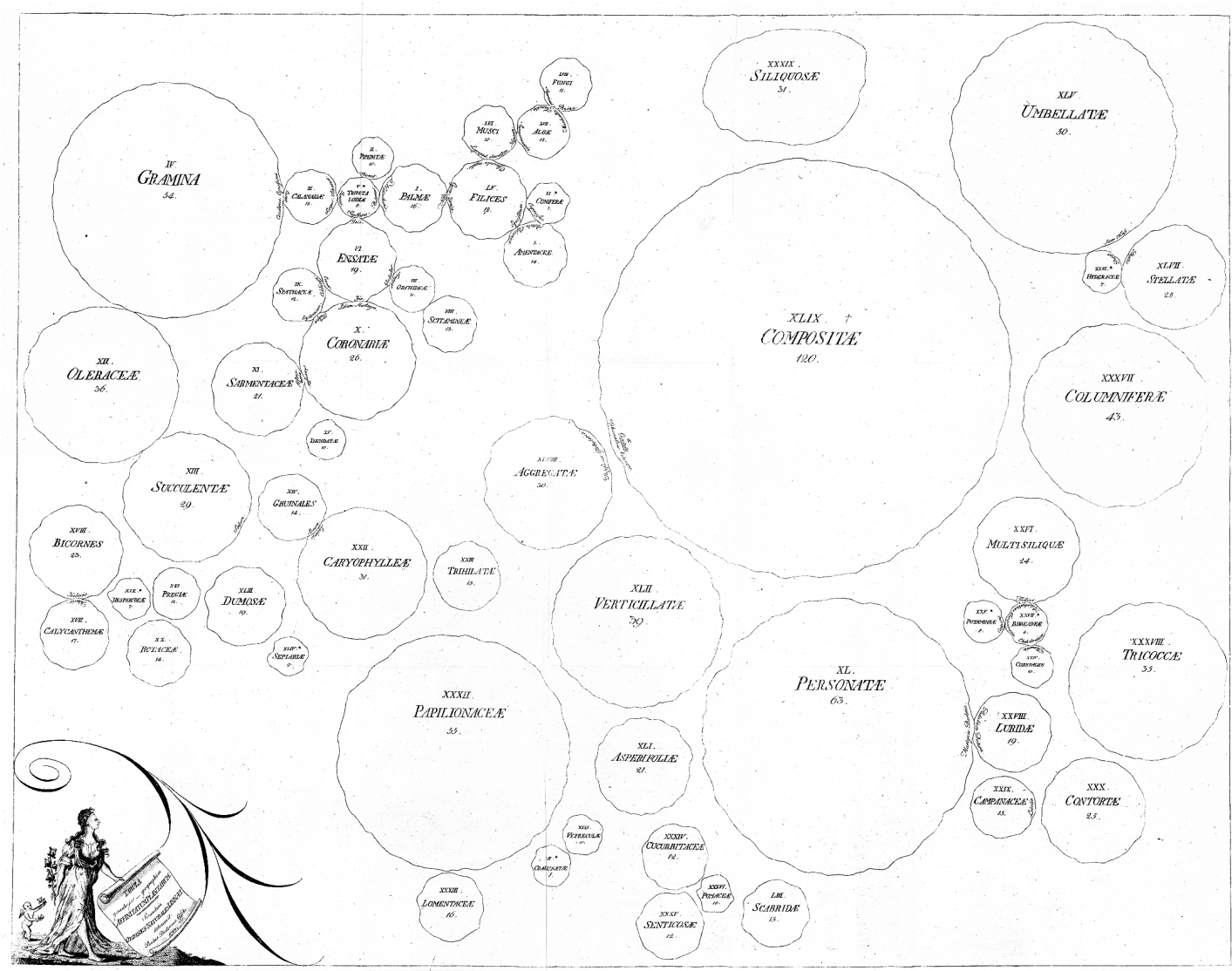

Figure 12.5 'Tabula genealogico-geographica Affinitatum Plantarum' from Caroli Linnaei Praelectiones in ordines naturales plantarum, edited by P. D. Giseke (Hamburg, 1790). The circles represent 'natural orders' or plant families, their size the number of genera they contain, which is also noted in the centre of each of them, alongside the family's name and Roman numeral. The relative position of each circle indicates its taxonomic relationship with other families, sometimes highlighted by inscribing the names of closely related genera on the inside of circles where they approach each other. Courtesy Uppsala University Library.

patchy, and that the basis for sweeping generalisations is slim. More research needs to be done to understand how exactly natural history knowledge was made to circulate globally, how it was stored in metropolitan institutions and individual collections, and how it was retrieved time and again to be redeployed in new contexts. I hope I have demonstrated, however, that the study of the tools and 
infrastructures of classical natural history's 'information economy' promises to advance our understanding of this crucial period in the history of the life sciences. It is well known that the irregular patterns of species distribution that we saw emerging, on a small scale, in Forster's Catalogue, and, on a larger scale, in Linnaeus's attempts to chart out the 'natural affinities' among plants, inspired Alexander von Humboldt, Augustin Pyramus de Candolle and Charles Lyell in the early nineteenth century to concede the possibility that species had been created independently of each other, at different times and places, and enjoyed differential success in the 'struggle for life', and that the same patterns also formed one of the chief explananda of Darwin's theory of evolution by natural selection. Tables, charts and maps of increasingly complex format played a crucial role in these explorations. $^{46}$ At the same time, however, naturalists used these tools to meticulously take account of their own achievements and those of others, hence articulating themselves as a recognised, and recognisable, community with new professional roles and regulated ways of distributing credit.

The infrastructure of 'labels' and 'containers' that was created by Linnaean paper tools, in other words, began to acquire a life of its own, both as a research object, revealing phenomena that could not have been revealed without it, and as a social instrument, articulating communities that would not have formed without it. The urge to document everything in writing, some anthropologists have claimed, is at the heart of the difference between 'the West' and 'the Rest'. ${ }^{47}$ A cultural history of natural history that attends to this aspect of scientific practice, therefore, has the potential to reveal that natural history, its techniques, and the affects and aspirations associated with these, form a central element of modernity despite their enduring antiquarian image.

\section{Further reading}

Blair, A., 'Note taking as an art of transmission', Critical Inquiry, 31 (2004), pp. 85-107.

Daston, L., 'Taking note(s)', Isis, 95 (2004), pp. 443-8.

Delbourgo, J. and Müller-Wille, S., 'Introduction to focus section "Listmania"', Isis, 103 (2012), pp. 710-15.

Krämer, F., 'Ulisse Aldrovandi's Pandechion Epistemonicon and the use of paper technology in Renaissance natural history', Early Science and Medicine, 19 (2014), pp. 398-423. 
McOuat, G. R., 'Cataloguing power: delineating "competent naturalists" and the meaning of species in the British Museum', British Journal for the History of Science, 34 (2001), pp. 1-28.

te Heesen, A., The World in a Box: The Story of an Eighteenth-Century Picture Encyclopedia (Chicago, 2002).

Thomas, J. M., 'The documentation of the British Museum's natural history collections, 1760-1836', Archives of Natural History, 39 (2012), pp. 111-25. 